If a nation must have human spaceflight — and it seems that, in terms of practical politics, the United States must - then travel to such interesting places seems the best of the available goals. That makes Constellation the way forwards. There is, however, a significant gap between the last shuttle flight next year and the first launch of an Orion capsule to the space station, which might not take place until 2015. Such a gap was planned; indeed, it was one of the space vision's braver aspects, recognizing that creating a new system while running the old one was not a viable option. Yet delays in Constellation's development mean that the gap is getting longer, leaving the United States dependent on Russia to deliver people to the space station in the interval. That perceived ignominy, combined with the job upheaval threatened by the demise of the shuttle, seems to some in Congress a reason to stretch out the shuttle's old age.
It is not. The basic logic remains sound: closing one human spaceflight operation before the next is functional saves money and ensures focus. NASA's next administrator, whenever he or she is finally named and confirmed, should be free to concentrate on meeting the goals that Constellation was designed for - without the distraction of also having to drag out the shuttle programme.

That administrator should also make it clear that human spaceflight, although a huge part of NASA's legacy, is not the overarching justification for the agency's existence. NASA also has a great deal of urgent work to do in studying Earth from orbit - and in providing new visions of the Universe beyond Earth. Servicing the Hubble might have been the best thing the shuttles did. But the images and knowledge provided by the Hubble, more than the mostly routine missions of the shuttle, are closer to the essence of what the space programme is there for.

\section{Doing good, 50 years on}

Its attack on poverty and arrogance is what makes C. P. Snow's 'two cultures' lecture relevant today.

/ / did not expect much. Plenty of people were saying similar things. It seemed to me to be a time when one should add one's voice." Thus did the English scientist-turned-administratorturned-novelist Charles Percy Snow recall his anticipations 50 years ago today, when giving his 1959 Rede lecture on 'the two cultures'. But by the time of his 1964 essay 'The Two Cultures: and a Second Look', it was clear that a nerve had been struck in many countries.

Many aspects of his lecture refer to a time long gone. Its attack on the lack of intellectual interest in the world of applied science and trade can hardly be said to apply now in his home country, transformed as it has been in its attention to technology transfer and investment. Michael Frayn, Tom Stoppard, John Updike and others have shown, in vivid and diverse contrast to his era, how the literary imagination has been fired by science (see page 34 ).

Many senior policy-makers might still have difficulty in reciting the second law of thermodynamics - Snow's notorious test of essential and neglected scientific awareness. But, thanks to extensive public discussion and access via the Internet, a great many of them are well aware of what research has to say about issues that immediately concern them, in climate, stem cells and much else.

Indeed, the boundaries between the arts and the sciences - and between the sciences themselves - are more porous than ever. Yes, multidisciplinarity poses some substantial challenges in some domains (see page 32 ), especially when it comes to training. But those who bring disciplines together in the pursuit of scientific and technical answers find that the best people to have on board are those with deep specialized knowledge, and that such individuals can usually find a place in well-led collaborations.

One seldom-discussed aspect of Snow's talk is his discussion of the rich and the poor - a subject he subsequently wished he had expressed better. "With good fortune," he wrote in his 1964 essay, "we can educate a large proportion of our better minds so that they are not ignorant of ... the remediable suffering of most of their fellow humans, and of the responsibilities which, once they are seen, cannot be denied."

It is in this territory alone that Snow's lecture truly has an edge today. On the one hand he would have celebrated the descendants of the physicists such as Ernest Rutherford whom he insightfully wrote about elsewhere - the purest of the pure in their scientific goals. The combination at CERN - Europe's particle-physics laboratory near Geneva, Switzerland - of world-class engineering with ambitions to seek deeper levels of the laws of nature would have inspired Snow.

Yet Snow would not have approved of the narrow-mindedness of some researchers who consider the significant costs of their work to be no more than their due from society, nor of their blind resentment when its value is questioned. Nature champions expensive science that seeks to answer the deepest questions about matter and the Universe. But it also endorses a spirit, as expressed in the final chapter of 'The Two Cultures', that gives just as much priority to scientists' responsibility to address humankind's most pressing problems.

What Snow urged in particular was an awareness of the problems of poor countries - and of putting scientists at the disposal of solving those problems, for reasons both moral and strategic. $\mathrm{He}$ expressed the disparities between rich and poor countries in terms of average lifespan. Those disparities may have shrunk but are still unacceptably large. Today's global threats may make them worse.

Snow's overriding messages - whether about awareness of artistic and scientific experience or about the applied sciences or about 'remediable suffering' - was that the best and the brightest should not be blinkered. That message still has resonance. Narrow-mindedness and any intellectual arrogance that lies behind it remain as unforgivable now as they were half a century ago.

Join the debate at Nature Network at www.tiny.cc/opinion191 to add your views and comment on these articles. 